\title{
Influence of zinc concentration on band gap and sub-band gap absorption on ZnO nanocrystalline thin films sol-gel grown
}

\author{
Munirah $^{1, *}$, Ziaul RaZa Khan ${ }^{2}$, Anver AZIZ ${ }^{1}$, Mohd. Shahid Khan ${ }^{1}$, M.U. Khandaker ${ }^{3}$ \\ ${ }^{1}$ Laser Spectroscopy Lab., Department of Physics, Jamia Millia Islamia, New Delhi-110025, India \\ ${ }^{2}$ Department of Physics, College of Science, University of Hail, Hail-2440, Kingdom of Saudi Arabia \\ ${ }^{3}$ Department of Physics, Faculty of Science, University of Malaya, 50603, Kuala Lumpur, Malaysia
}

\begin{abstract}
$\mathrm{ZnO}$ thin films were fabricated on quartz substrates at different zinc acetate molar concentrations using sol-gel spin coating method. The samples were characterized using X-ray diffraction, field emission scanning electron microscope, UV-Vis spectroscopy, FT-IR spectroscopy and photoluminescence spectroscopy. Sub-band gap absorption of ZnO thin films in the forbidden energy region was carried out using highly sensitive photothermal deflection spectroscopy (PDS). The absorption coefficients of $\mathrm{ZnO}$ thin films increased in the range of $1.5 \mathrm{eV}$ to $3.0 \mathrm{eV}$, upon increasing zinc concentration. The optical band gaps were evaluated using Tauc's plots and found to be in the range of $3.31 \mathrm{eV}$ to $3.18 \mathrm{eV}$. They showed the red shift in the band edge on increase in zinc concentration. The PL spectra of $\mathrm{ZnO}$ thin films revealed the characteristic band edge emission centered at the $396 \mathrm{~nm}$ along with green emission centered at the $521 \mathrm{~nm}$.
\end{abstract}

Keywords: ZnO; photothermal deflection spectroscopy; sub-band gap; sol-gel

(C) Wroclaw University of Science and Technology.

\section{Introduction}

Recently, transparent conducting oxides received considerable interests due to their excellent physical, optical and electrical properties. Among them, $\mathrm{ZnO}$ is a promising candidate of II-VI group semiconducting material with direct band gap of $3.30 \mathrm{eV}$ and high exciton binding energy of $60 \mathrm{meV}$ at room temperature. Thin films of $\mathrm{ZnO}$ are biocompatible, with high chemical and thermal stability and have superb physical properties. They have been used in various applications, such as surface acoustic waves, gas sensors, diode lasers and optoelectronics [1-4]. Such outstanding properties and applications of $\mathrm{ZnO}$, made it popular among material researchers. Nowadays, $\mathrm{ZnO}$ thin films have been under extensive investigation for reliable optoelectronic device manufacturing. $\mathrm{ZnO}$ thin films have been grown by various methods, such as rf sputtering [5], PLD [6], spray pyrolysis [7],

*E-mail: mufazzalmunirah@gmail.com sol-gel [8]. Sol-gel method is found to be the most suitable for the growth of $\mathrm{ZnO}$ thin films, as it allows fabrication of thin films with improved structural, optical and electrical properties. From physical appearance, the films are uniform with better adhesion compared to the films grown by various physical vapor deposition systems but the defect density still remains significant. In order to fabricate reliable optoelectronic devices, it is necessary to understand the origin and control the defect growth rate. Absorption coefficients of thin films, evaluated from the standard transmittance/reflectance (T\&R) or ellipsometric measurements, are usually an overprediction due to the optical scattering, refraction and many other optical phenomena. The reduced optical intensities, caused by the earlier mentioned phenomena, are assumed to be due to optical absorption in the films only, which is totally incorrect. For developing optical devices, e.g. planar optical waveguides, photovoltaic devices, light detectors, LEDs and photonic crystals, accuracy of optical parameters matters 
a lot. It is well known that the photothermal deflection spectroscopy is used due to its very high sensitivity $\alpha \mathrm{d}$ in the range of $10^{-4}$ to $10^{-7}$, (where $\alpha$ is the absorption coefficient and $\mathrm{d}$ is the thickness of the film). It is very helpful technique in order to evaluate very weak optical absorption arising due to defects created in the forbidden region. Optical absorption spectra measured by PDS are of pure absorption type, free from any kind of optical scattering and refraction. The theoretical investigation of band gap has been carried out on $\mathrm{ZnO}$ material by various researchers using density functional theory with the generalized gradient approximation GGA and GGA + U [9]. DFT computations of $\mathrm{ZnO}$ revealed its electronic structure with direct band gap along $\Gamma$ point transition and the value of optical band gap of $\sim 3.4 \mathrm{eV}$. The experimentally obtained optical band gap of $\mathrm{ZnO}$ showed good agreement with the theoretically reported value [10-12]. Also, DFT computations of $\mathrm{ZnO}$ revealed a large number of transition levels due to intrinsic defects. These transition levels may be due to both zinc and oxygen vacancies. However, measurement of such a weak optical absorption is a problem in itself. Currently, photothermal deflection spectroscopy technique has been employed widely for the measurement of weak absorbance in semiconducting material thin films [13, 14]. The influence of zinc concentration on the optical absorption in the subband gap of $\mathrm{ZnO}$ thin films has been studied very scarcely. In this work, $\mathrm{ZnO}$ thin films with different zinc concentrations were fabricated on a quartz substrate by sol-gel spin coating method. The influence of zinc concentration on the optical band gap and sub-band gaps were investigated in details.

\section{Experimental}

\subsection{Sample preparation and its character- ization}

The solutions were prepared using analytical grade zinc acetate dihydrate, 2-methoxyethanol and monoethanolamine. All the chemicals were purchased from Sigma Aldrich Pvt., Ltd. The molar ratio of MEA to zinc acetate was kept at 1:0 and concentration of zinc acetate was varied in the range of $0.35 \mathrm{M}$ to $0.95 \mathrm{M}$. The prepared solution was stirred at $65{ }^{\circ} \mathrm{C}$ for 90 min to yield a clear and homogeneous solution. The freshly prepared solution was used for the coatings. The films were deposited on ultrasonically cleaned quartz substrates by spin coating unit which was rotated at $3000 \mathrm{rpm}$ for $30 \mathrm{~s}$. The films were annealed at $400{ }^{\circ} \mathrm{C}$ in oxygen atmosphere. The detailed sample preparation flow chart is presented in Fig. 1. The structural properties of the thin films were investigated using the X-ray diffractometer model PW3710 which was operated at $30 \mathrm{kV}$ and $30 \mathrm{~mA}(\mathrm{Cuk} \alpha$ radiation, $\mathrm{k}=1.542 \AA)$. The transmittance spectra of the films were recorded using the UV-Vis double beam spectrophotometer model JASCO V-570. The surface morphology of the films was recorded using JEOL JSM-6510LV. Photoluminescence spectra of the samples were recorded using the Horiba Jobin Yvon $800 \mathrm{UV}$ Micro-Raman Spectrometer with $\mathrm{He}-\mathrm{Cd}$ laser of $325 \mathrm{~nm}$ wavelength.

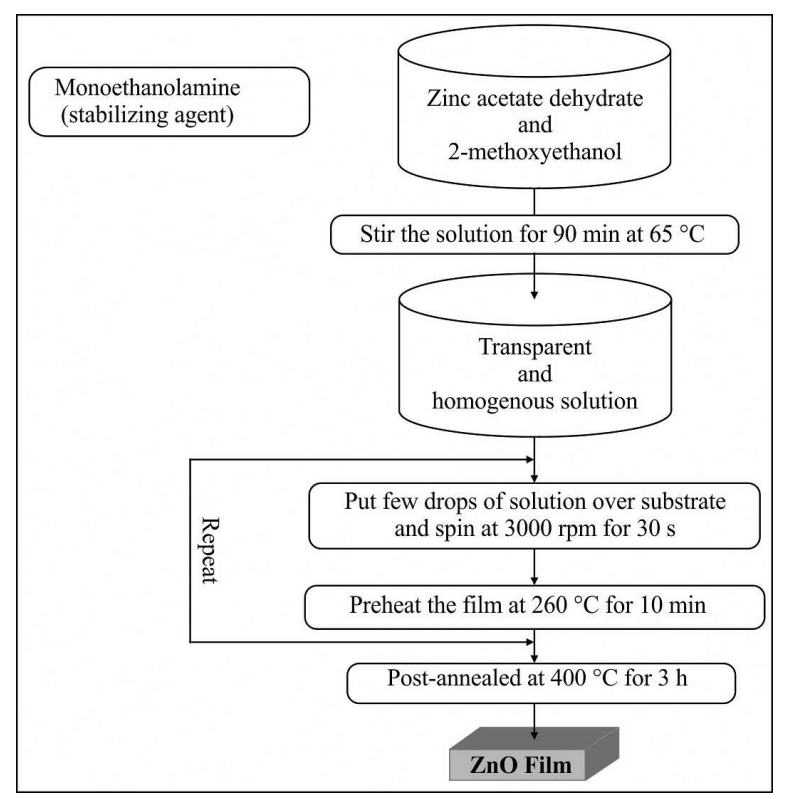

Fig. 1. Flow chart of preparation of $\mathrm{ZnO}$ thin films.

\subsection{Photothermal deflection spectroscopy}

The photothermal deflection measurement setup is aligned in two different ways: one is collinear arrangement, and the other one is transverse arrangement. Transverse PDS setup for 


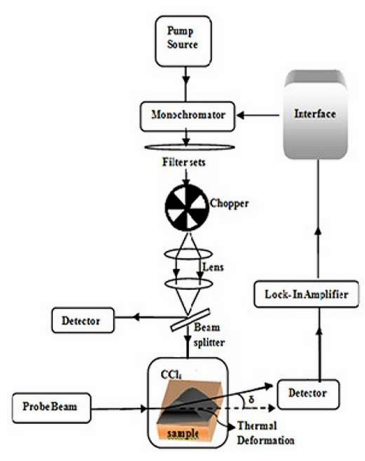

(a)

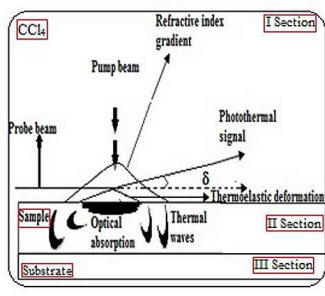

(b)
Fig. 2. (a) Schematic diagram of PDS setup, (b) the interface geometry of the pump and probe beam.

the evaluation of weak optical absorption spectra in forbidden energy region was used. The schematic diagram of transverse photothermal deflection spectroscopy setup is shown in Fig. 2. A tungsten-halogen lamp was used for pumping the sample which generated heat within and in the vicinity of the sample surface. The monochromator was used to block the dispersed light. Light beam was further passed through a low-pass filter and then focused over $\mathrm{ZnO}$ thin film. The light was mechanically chopped at $20 \mathrm{~Hz}$. The $\mathrm{CCl}_{4}$ liquid has been used as a surrounding medium due to its very high coefficient of variation of refractive index with temperature of $\left(\frac{\delta \mathrm{n}}{\delta \mathrm{T}}=5 \times 10^{-4} \mathrm{~K}^{-1}\right)$. To confirm that the surrounding material did not influence the film surface and finally the PDS signal, the optical absorbance measurement of the films immersed in $\mathrm{CCl}_{4}$ for $5 \mathrm{~h}$ was also carried out, which showed no significant change. The He-Ne laser with the power of $5 \mathrm{~mW}$ was used as a probe beam, just grazing the sample surface. The lock-in amplifier was used to amplify the detector signal. The PDS signal was recorded using four-quadrant detector.

\subsection{Basic principle of sub-band gap mea- surement by PDS}

The weak optical absorbance in the subband gap of semiconductor thin films has been investigated using the photothermal deflection spectroscopy, because PDS is a very sensitive and accurate compared to other techniques. Recently, the sub-band gap investigation in semiconductor thin films has been reported by various researchers [15, 16]. Azis et al. [17, 18] investigated the sub-band gap of AlQ thin films deposited at different deposition conditions using PDS technique. The working principles of PDS depend mainly on the photothermal excitation of samples, hence, a sample gets heated periodically. Surrounding material produces a refractive index gradient near the surface of the films. The probe laser beam grazed the surface of the sample and got deflected due to the refractive index gradient. The amplitude of this periodic deflection was monitored with a quadrant detector and a differential AC synchronous detection scheme. Absorption of pump beam can be measured for different wavelength regions. The modulated amplitude of PDS signal $P_{\mathrm{S}}$ is directly related to the absorption coefficient $\alpha$ [19]:

$$
P_{s} \propto n^{-1} \frac{\partial n}{\partial T} I_{i n c}(1-\exp (-\alpha t))
$$

where $\mathrm{n}$ is the refractive index of material, and $\mathrm{I}_{\mathrm{inc}}$ is the incident power of the pump light at a given wavelength, $t$ is the thickness of thin film on the glass substrate. The expression 1 can be rewritten in the form:

$$
P_{s}=P_{s a t}(1-\exp (-\alpha t))
$$

where $\mathrm{P}_{\text {sat }}$ is the saturated amplitude which depends on the geometrical parameters of the experimental setup.

\section{Results and discussion}

\subsection{X-ray diffraction analysis}

The crystalline structure and preferred crystal orientation of $\mathrm{ZnO}$ thin films with different zinc concentrations, grown by sol-gel method, were investigated by the $\mathrm{X}$-ray diffraction patterns.

Fig. 3 shows the X-ray diffraction patterns of $\mathrm{ZnO}$ thin films with different zinc concentrations in the range of $2 \theta \approx 10^{\circ}$ to $70^{\circ}$. The growth of thin films is observed along the $\left(\begin{array}{lll}1 & 0 & 0\end{array}\right)$ and (l $\left.\begin{array}{lll}0 & 0 & 2\end{array}\right)$ planes at the angles $2 \theta \sim 31^{\circ}$ and $34^{\circ}$, 


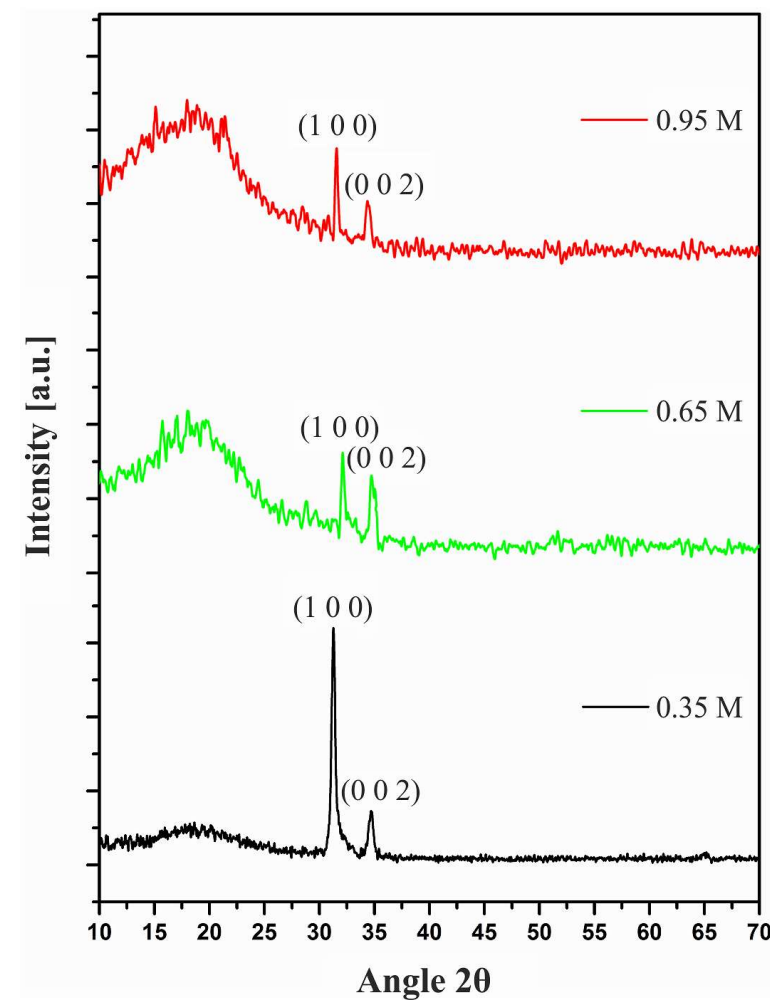

Fig. 3. XRD pattern of $\mathrm{ZnO}$ thin films with different zinc molar concentrations.

respectively. It implies the polycrystalline nature with hexagonal wurtzite structure of the films [20]. All the samples exhibit strong peak intensity along the $\left(\begin{array}{lll}1 & 0 & 0\end{array}\right)$ plane. This confirms the preferential growth of the films along (1 0 l 0 ) plane. From Fig. 3, the effect of zinc concentration on XRD patterns of $\mathrm{ZnO}$ thin films is clearly observed. The crystallinity and crystal orientation have changed with the increasing zinc acetate concentration. Thin films grown with $0.35 \mathrm{M}$ zinc concentration show higher crystallinity than thin films with higher zinc concentration viz. $0.65 \mathrm{M}$ and $0.95 \mathrm{M}$. Average crystallite size of the thin films, estimated using Debye-Scherer formula, were found to be $\sim 30 \mathrm{~nm}$, $35 \mathrm{~nm}$ and $51 \mathrm{~nm}$ for $0.35 \mathrm{M}, 0.65 \mathrm{M}$ and $0.95 \mathrm{M}$ zinc concentration, respectively. It was observed that the crystallite size of the films increases with the increase in zinc concentration. Similar results were reported on the effect of zinc acetate concentration on crystallite size by Brien et al. [11]. The structural parameters of the thin films are presented in Table 1.
Table 1. Structural parameters, thickness and band gap of $\mathrm{ZnO}$ thin films with different zinc acetate concentrations.

\begin{tabular}{lcccc}
\hline $\begin{array}{c}\text { Zinc acetate } \\
\text { concentration }\end{array}$ & \multicolumn{2}{c}{ Growth } & Crystallite Thickness & Band \\
size [nm] & [nm] & gap [eV] \\
\hline \hline $0.35 \mathrm{M}$ & $\left(\begin{array}{lll}1 & 0 & 0\end{array}\right)$ & 30 & 190 & 3.31 \\
$0.65 \mathrm{M}$ & $\left(\begin{array}{lll}1 & 0 & 0\end{array}\right)$ & 35 & 250 & 3.24 \\
$0.95 \mathrm{M}$ & $\left(\begin{array}{llll}1 & 0 & 0\end{array}\right)$ & 51 & 300 & 3.18 \\
\hline
\end{tabular}

\subsection{SEM and EDX analysis}

SEM micrographs of $\mathrm{ZnO}$ thin films with different zinc concentrations are shown in Fig. 4a. The surface morphology of the films has changed with the increase in molar concentration of zinc. The films deposited at $0.35 \mathrm{M}$ and $0.95 \mathrm{M}$ showed the round particle shape and average particle size in nanorange of $\sim 30 \mathrm{~nm}$ to $40 \mathrm{~nm}$. The film deposited at zinc acetate concentration of $0.65 \mathrm{M}$ showed non-uniform surface morphology with rougher surface than other films. All samples showed no cracks and voids and also revealed good adhesion of the material to the substrates. The EDX spectra of the films in the energy range of $1 \mathrm{keV}$ to $20 \mathrm{keV}$ are shown in Fig. 4b. It can be observed from the EDX spectra that the elemental composition of the films consists of zinc and oxygen elements.

\section{3. $\quad$ FT-IR analysis}

Fig. 5 shows FT-IR spectra of $\mathrm{ZnO}$ thin films with different zinc concentrations. The characteristic $\mathrm{ZnO}$ absorption bands are centered at $488 \mathrm{~cm}^{-1}$. However, a lower frequency peak of low intensity at $\sim 759 \mathrm{~cm}^{-1}$, related to the $\mathrm{ZnO}$ stretching mode, is observed in the present spectra. We observe various other peaks due to the solvent effects. The absorption bands are centered at $1423 \mathrm{~cm}^{-1}$ due to the $\mathrm{O}-\mathrm{H}$ bending of the hydroxyl group. The absorption peaks at $1581 \mathrm{~cm}^{-1}$ are due to the acetate group $\left(\mathrm{CH}_{3} \mathrm{COO}^{-}\right)$. From Fig. 5, it can be seen that on increasing zinc acetate molar concentration of the growth solutions, absorbance peak intensity, due to the acetate group, has increased. It confirms the enhancement of acetate group binding across $\mathrm{ZnO}$ molecules with the increase in zinc acetate concentration in the growth solutions [21]. 

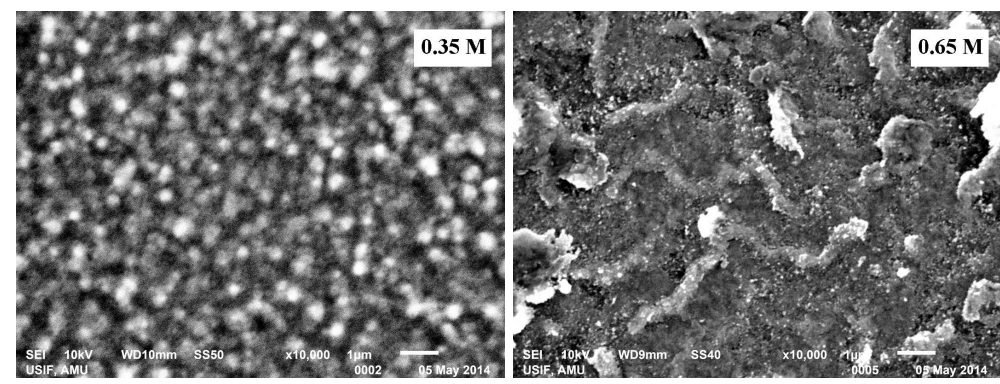

(a)
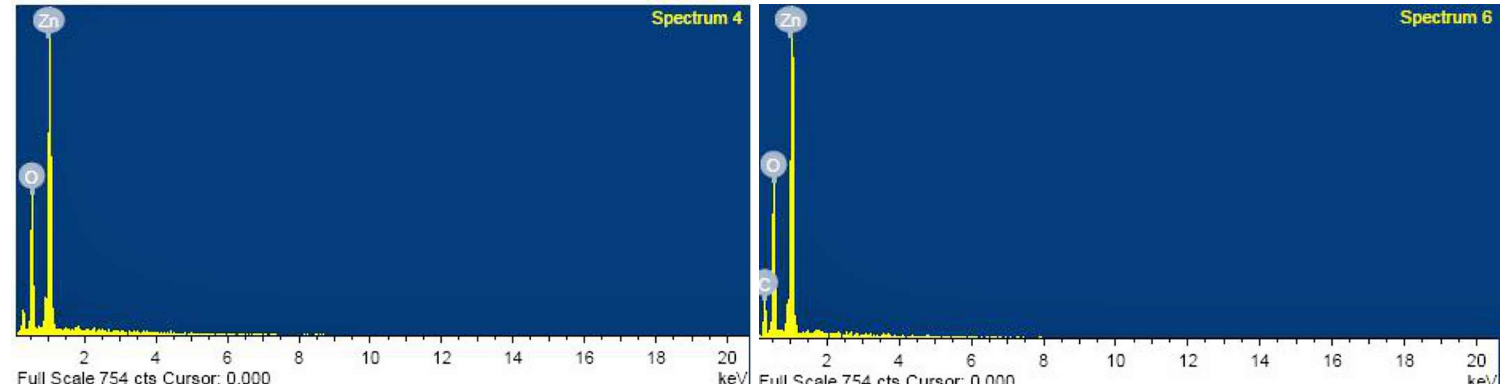

(b)

Fig. 4. (a) SEM micrographs of $\mathrm{ZnO}$ thin films with different zinc molar concentrations, (b) EDX spectra of $\mathrm{ZnO}$ thin films.

The peak centered at the range of $2800 \mathrm{~cm}^{-1}$ to $3000 \mathrm{~cm}^{-1}$ arises due to the $\mathrm{C}-\mathrm{H}$ stretching, while the one at $3380 \mathrm{~cm}^{-1}$ arises due to the $\mathrm{O}-\mathrm{H}$ stretching.

\subsection{UV-Vis analysis}

The absorbance spectra of $\mathrm{ZnO}$ thin films, recorded in the range of $200 \mathrm{~nm}$ to $800 \mathrm{~nm}$, are shown in Fig. 6. From Fig. 6, the effect of zinc concentration on band edge of the thin films can be clearly observed. On increasing zinc concentration from $0.35 \mathrm{M}$ to $0.95 \mathrm{M}$, red shift is observed in the band edge of the films. In addition, significant amount of absorbance has been detected in forbidden energy gap region. The absorbance in the forbidden energy gap region has increased with the increase in zinc concentration. It may be due to the oxygen vacancy created during the growth with the increase in $\mathrm{Zn}$ concentration or defect states.

The absorption coefficients of $\mathrm{ZnO}$ thin films with different zinc concentrations in photon energy range of $1.5 \mathrm{eV}$ to $5.0 \mathrm{eV}$ are shown in Fig. 7. The band gaps of $\mathrm{ZnO}$ thin films with different zinc concentrations were calculated using the Tauc's

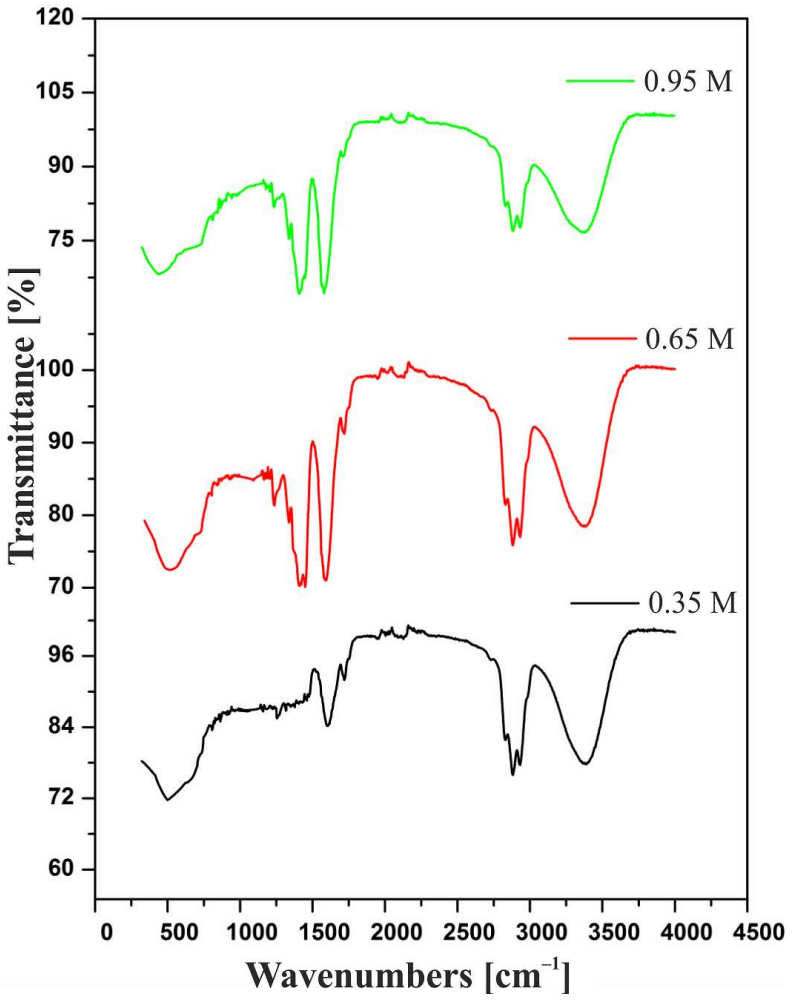

Fig. 5. FT-IR spectra of $\mathrm{ZnO}$ thin films with different zinc concentrations. 


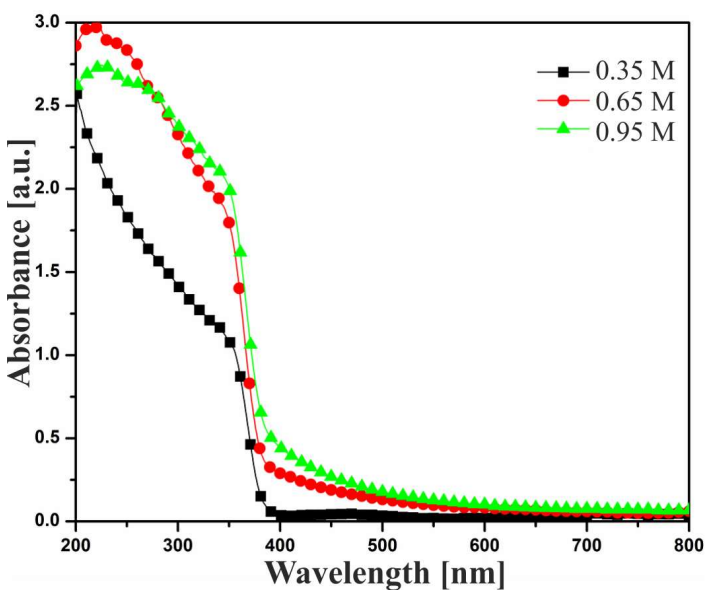

Fig. 6. Absorbance spectra of $\mathrm{ZnO}$ thin films with different zinc concentrations.

plots. The method of band gap estimation from absorbance spectra was reported in the literature [22].

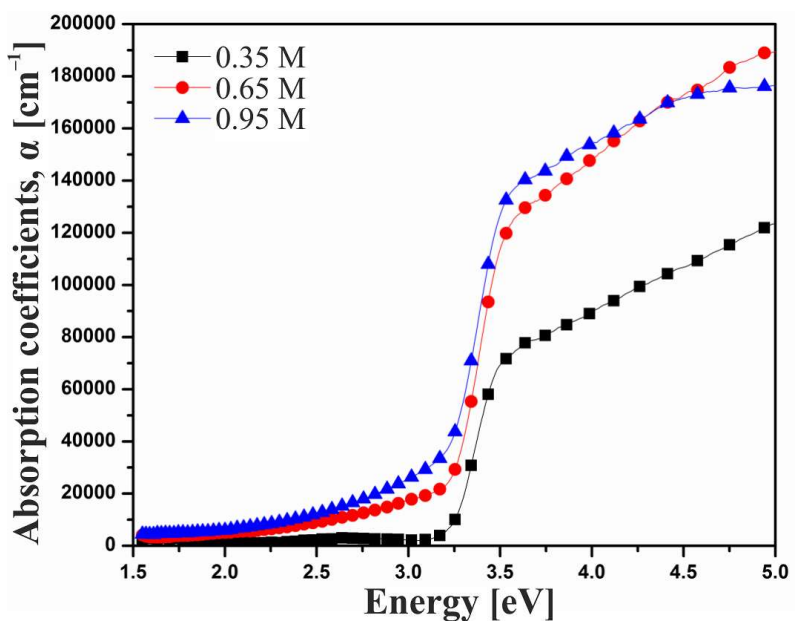

Fig. 7. Absorption coefficients of $\mathrm{ZnO}$ thin films with different zinc concentrations.

The Tauc's plots of $\mathrm{ZnO}$ thin films with different zinc concentrations are shown in Fig. 8. The values of band gaps of $\mathrm{ZnO}$ thin films were found to be from $3.18 \mathrm{eV}$ to $3.31 \mathrm{eV}$. It shows the good agreement with the earlier reported values [23, 24]. Fig. 8 clearly illustrates that the band gap of the thin films decreases with the increase in zinc concentration. It may be due to the increase in crystallite sizes with the increase in zinc concentration.

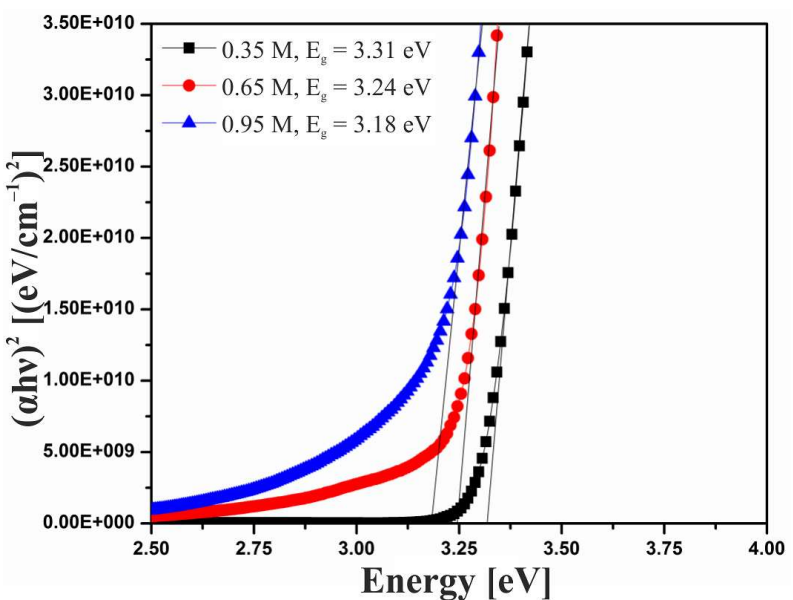

Fig. 8. Tauc's plots of $\mathrm{ZnO}$ thin films with different zinc concentrations.

This decrease in band gap may be due to the high content of $\mathrm{Zn}$, as compared to oxygen in $\mathrm{ZnO}$ binary system.

\subsection{Sub-band gap of $\mathrm{ZnO}$ thin films}

Sub-band gap optical absorption of $\mathrm{ZnO}$ thin films was investigated using photothermal deflection spectroscopy. The sub-band gap optical absorption coefficients of $\mathrm{ZnO}$ thin films with different zinc concentrations are shown in Fig. 9. Fig. 9 illustrates that the absorption coefficients of the films increase in the forbidden energy gap region with the increase in zinc concentration. In band gap energy region, absorption coefficient becomes saturated. Our main aim is to understand the cause of weak absorption in the sub-band gap energy region. The absorption coefficients of the films in the energy range of $1.5 \mathrm{eV}$ to $3.30 \mathrm{eV}$ measured by PDS can be divided mainly into two parts. Part I shows high absorption coefficients because this region approaches to the band gap energy region. Part II of the spectra reveals significant absorption coefficients in forbidden gap energy region. Now, we focus on this weak absorption in forbidden energy gap region. This absorption may arise due to two main factors in thin film inorganic semiconductor material: one is the surface states, and the other one is impurities addition during the growth. The surface states in inorganic semiconductor 
material develop due to following reasons: (1) Tamm-Shockley states resulting from breaking asymmetry of the lattice at the surface; (2) formation of dangling bonds on the surface; (3) impurities and adsorbate induced surface states. Present investigations strongly suggest that the enhancement in sub-band gap absorption coefficients can be attributed to the dangling bonds formation on the surface of thin films and impurities adsorbate induced surface states.

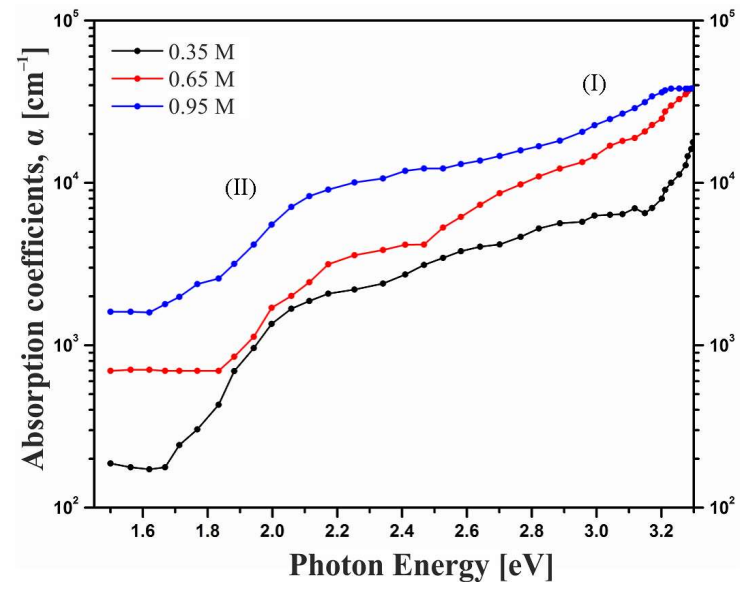

Fig. 9. Absorption coefficients $\alpha$ of $\mathrm{ZnO}$ thin thin films with different zinc concentrations (from PDS) as a function of photon energy in the energy range of $1.5 \mathrm{eV}$ to $3.3 \mathrm{eV}$.

\subsection{Photoluminescence}

The photoluminescence spectroscopy is the best tool to investigate the exact energy levels of grown semiconducting nanomaterial thin films. The effect of zinc concentration on PL of $\mathrm{ZnO}$ nanocrystalline thin films was investigated in details. The room temperature photoluminescence spectra of $\mathrm{ZnO}$ thin films grown with different zinc concentrations are shown in Fig. 10. The significant effect of zinc concentration on emission properties of $\mathrm{ZnO}$ thin films is clearly observed. All $\mathrm{ZnO}$ thin films exhibit near band edge emission which is centered in the UV region of $\sim 396 \mathrm{~nm}$ [25]. The strong peak at $396 \mathrm{~nm}$ originates from excitonic recombination. Form Fig. 10, it can be observed that the peak intensity of the near band edge emission decreases with the increase in zinc concentration. It may be caused by the change in crystallinity with an increase in zinc concentration. In addition, second peak in PL spectra can be clearly observed in visible green region of solar spectrum. This sharp intense peak in green emission, which is centered over $\sim 521 \mathrm{~nm}$, may be ascribed to the transition of electrons from singly charged oxygen vacancy to zinc vacancy sites [26]. The PL spectra of $\mathrm{ZnO}$ thin films were found to be similar except the differences in their intensities corresponding to the green emission.

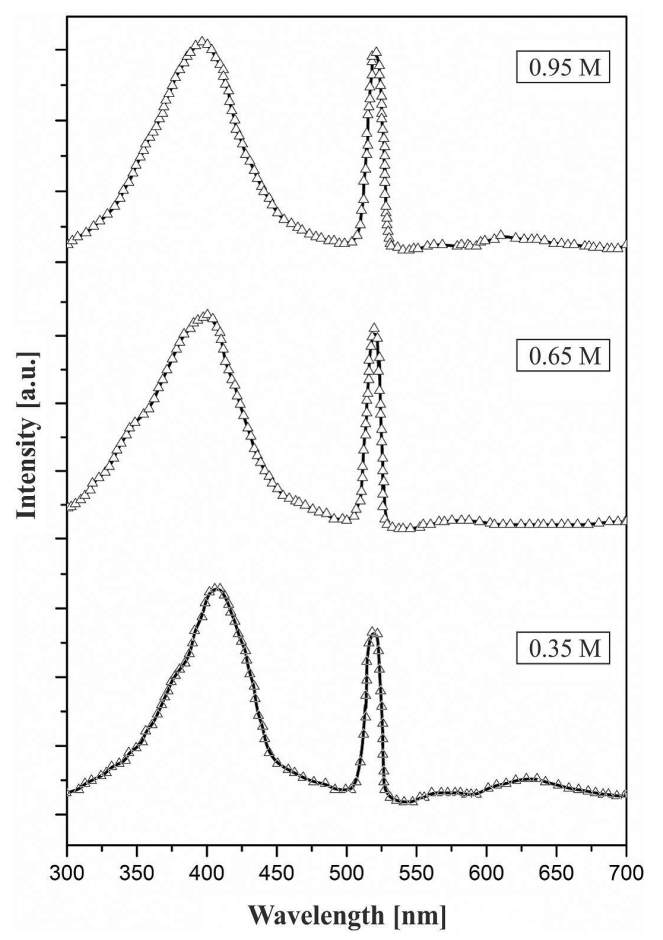

Fig. 10. Photoluminescence spectra of $\mathrm{ZnO}$ thin films grown from different zinc concentration sols.

From Fig. 10, it can be seen that on increasing zinc concentration in the growth solution, the characteristic band edge emission peak shows red shift with enhancement in green emission, especially for $0.95 \mathrm{M}$ zinc concentration [27]. Photoluminescence properties of nanosize material greatly depend upon its surface properties. The surface states formation is directly related with the defects and adsorption of impurities on the surface. In case of $\mathrm{ZnO}$ growth from zinc acetate precursor, acetate group can be adsorbed on the surface of $\mathrm{ZnO}$ layers. The main source of acetate groups is the zinc acetate precursor. Chain type structures and 
unidentate formation may be increased because of the presence of acetate groups. We can conclude on the basis of above discussion that the enhancement in the emission in visible region for $0.95 \mathrm{M}$ samples is mainly caused by the surface states developed on the films surface due to adsorption of acetate groups and forming chain-like structures [28].

\section{Conclusions}

In conclusions, $\mathrm{ZnO}$ nanocrystalline thin films with different zinc concentrations were fabricated on quartz substrates via sol-gel spin coating method successfully. The films showed polycrystalline nature with hexagonal wurtzite structure and preferred orientation along (llll 100$)$ plane. The crystallinity of the films degraded with the increase in zinc concentration. Band gap of the films decreased with an increase in zinc concentration. This was attributed to the creation of oxygen vacancies with the increase in zinc concentration. The subband gap absorption increased with the increase in zinc concentration gradually in the energy region of $1.0 \mathrm{eV}$ to $1.8 \mathrm{eV}$. This enhancement in sub-band gap optical absorption might be caused by dangling bonds formation and acetate group impurities adsorbed on the surface which led to the surface states. FT-IR spectra confirmed the acetate group presence in the thin films and their increase with the increase in zinc molar concentration. The photoluminescence spectra of the thin films showed the enhancement in green emission with the increase in zinc concentration.

\section{Acknowledgements}

This work was financially supported by the University Grants Commission of India. One of the authors, Munirah, acknowledges the USIF Center of Aligarh Muslim University Aligarh, India, to extend the SEM characterization facility.

\section{References}

[1] Wang Q.J., Pflugl C., Andress W.F., Ham D., Capasso F., Yamanishi M., J. Vac. Sci. Technol. 26, (2008), 1848

[2] Suchea M., Christoulaski S., Moschovis K., KATSARAKIS N., KIRIAKIDIS G., Thin Solid films, 512 (2006), 551.

[3] Mitra A., Thareja R.K., J. Appl. Phys., 89 (2001), 2025.
[4] Xua Q.A., Zhang J.W., Ju K.R., Yang X.D., Hou X., J. Cryst. Growth, 289 (2006), 44.

[5] Jayaraj M.K., Antony A., Ramachandran M., B. Mater. Sci., 25 (2002), 227.

[6] Perrie J., Millon E., Seiler W., Leborgne C.B., Cracium V., Albert O., Loulergue J.C., EtchePARE J., J. Appl. Phys., 91 (2002), 690.

[7] Lehraki N., Aida M.S., Abedb S., Attaf N., Attaf A., Poulanic M., Curr. Appl. Phys., 12 (2012), 1283.

[8] Kwon S.J., Park J.H., Park J.G., Appl. Phys. Lett., 87 (2005), 133112-3.

[9] Erhart P., Albe K., Klein A., Phys. Rev. B, 73 (2006), 205203-9.

[10] Khan Z.R., Khan M.S., Zulfequar M., Khan M.S., MSA, 2 (2011), 340.

[11] Brien S.O., Koh L.H.K., Crean G.M., Thin Solid Films, 516 (2008), 1391.

[12] Caglar M., Ilican S., Caglar Y., Thin Solid Films, 517 (2009), 5023

[13] Gracin D., Paramon J.S., Juraic K., Gajovic A., CEH M., Micron, 40 (2009), 56.

[14] Ambacher O., Rieger W., Ansmann P., AnGerer H., Moustakas T.D., Stutzmann M., Solid State Commun., 97 (1996), 365.

[15] Zhouy W., Xiey S., QIANy S., Wangy G., QIAnZ L., J. Phys.-Condens. Mat., 8 (1996), 5793.

[16] Beenken W.J.D., Herrmann F., Presselt M. Hoppe H., Shokhovets S., Gobsch G., Runge E., Phys. Chem. Chem. Phys., (2013), 16494.

[17] AZIZ A., NARASIMHAN K.L., Synthetic Met., 114 (2000), 133.

[18] AzIz A., Narasimhan K.L., Synthetic Met., 131 (2002), 71

[19] JACKSON W.B., AMER N.M., BOCCARA A.C., Fourier D., Appl. Optics, 20 (1981), 1333.

[20] Joshi B.N., Yoon H., Kim H.Y., OH J.H., SeOnG T.Y., James S.C., Yoon S.S., J. Electrochem. Soc., 159 (2012), 716.

[21] VAFAeE M., GHAMSARi M.S., Mater. Lett., 61 (2007), 3265.

[22] Khan M.M.S., AzIz A., Mater. Focus, 3 (2014), 55.

[23] KIm Y.S., TaI W.P., Shu S.J., Thin Solid Films, 491 (2005), 153.

[24] XU L., LI X., J. Cryst. Growth, 132 (2010), 851.

[25] Mondal O., Pal M., J. Mater. Chem., 21 (2011), 18354.

[26] Das S., Ghosh C.K., Dey R., Pal M., RSC Adv., 6 (2016), 236.

[27] Xu Z., Deng H., XIE J., Li Y., Li Y., J. Sol-Gel Sci. Techn., 36 (2005), 223.

[28] Sakohara S., Ishida M., Anderson M.A., J. Phys. Chem. B, 102 (1998), 10169. 